\title{
Multiple Liver Abscesses with Isolation of Streptococcus Intermedius Related TO A PyOgenic Dental INFECTION IN AN IMMUNO-COMPETENT PATIENT
}

\author{
A. Neumayr ${ }^{1}$, R. Kubitz ${ }^{1}$, J. G. Bode ${ }^{1}$, P. Bilk², D. Häussinger ${ }^{1}$ \\ ${ }^{1}$ Department of Gastroenterology, Hepatology and Infectiology, University Hospital Düsseldorf, Düsseldorf, Germany; \\ ${ }^{2}$ Institute of Radiology, University Hospital Düsseldorf, Düsseldorf, Germany
}

\begin{abstract}
Introduction: Streptococcus intermedius - a member of the Streptococcus anginosus group - is part of the normal microbial flora of the oral cavity. Despite being regarded as a harmless apathogenic commensal, Streptococcus intermedius has been described to cause abscesses in various locations of the body.

Case Presentation: We report the clinical case and course of treatment of a 18-year-old male patient presenting with multiple hepatic abscesses associated with an untreated pyogenic dental infection.

Conclusion: Streptococcus intermedius can cause liver abscesses emerging from dental infectious foci even in previously healthy patients without underlying innate or aquired immunodeficiency. The case illustrates the potential danger and underestimated risk associated with untreated dental infections.
\end{abstract}

Key words: Streptococcus intermedius, Streptococcus anginosus, liver abscess, dental infection

\section{INTRODUCTION}

Streptococcus intermedius is a member of the "Streptococcus anginosus group" (consisting of $S$. intermedius, S. constellatus, and $S$. anginosus), formerly also known as "Streptococcus miller group" or "Streptococcus intermedius group". Streptococcus intermedius is a spherical or ovoid, microaerophilic / anaerobic gram positive bacterium forming pairs or chains [1]. The members of the Streptococcus anginosus group are frequently found in the human oral cavity, where they are considererd to be harmless commensals. They can also colonize the throat, nasopharynx, gastrointestinal tract, and genitourinary tract (which probably represents spread from the oral cavity)[1]. Within the Streptococcus anginosus group, Streptococcus intermedius is most commonly found in dental plaques [2]. Members of the $S$. anginosus group are regularly isolated from dental abscesses [3, 4] and have frequently been found to cause local and metastatic purulent infections $[5,6]$. In particular Streptococcus intermedius has been reported to cause liver and brain abscesses (and rarely infective endocarditis) [2, 7-11]. As commensal organism of the intestinal tract members of the $S$. anginosus group have also been found to cause various infections within the abdominal cavity including liver abscesses, peri- tonitis, pelvic and subphrenic abscesses, appendicitis, abdominal wound infections and cholangitis $[5,12$, 13]. Aspiration of commensal oropharyngeal Streptococcus anginosus can lead to pneumonia, lung abscess, and pleural empyema [3, 14-17]. Other infections caused by members of the Streptococcus anginosuss group are peritonsillar abscesses [18], mediastinitis [19], osteomyelitis [3], septic arthritis [20], and soft tissue infections [3, 21, 22]. An interesting feature of Streptococcus intermedius is the ability to replicate more rapidly in an environment with other microbes (e.g. Eikenella corrodens and anaerobes): It has been shown in vitro, that Streptococcus intermedius grows exponentially in mixed culture with E. corrodens within 6 hours post inoculation, in comparison to 25 hours without E. corrodens [23]. A possible clinical correlate of such a mixed infection has been described [24]. In a murine model of pneumonia a synergistic effect between members of the $S$. anginosus group and oral anaerobes has been published (higher mortality, more histopathologic abnormalities and more viable bacteria in the lungs of mice with mixed infections than in the lungs of mice with monomicrobial infection) [14].

\section{Case Presentation}

A 18-year-old male patient with a history of right upper quadrant abdominal pain and remittent fever (up to $39.4^{\circ} \mathrm{C}$ ) was refered to our hospital with the diagnosis of multiple liver abscesses and the isolation of "grampositive cocci" from fine needle aspiration. On admisson the patient was on empirical intravenous antibiotic treatment with imipenem/cilastin and penicillin G administered via a right-jugular central venous catheter. Besides a history of surgery due to an umbilical hernia one year prior to admission the patient had no medical history (i.e. no history of infections), intravenous drug abuse, or travelling. On physical examination the patient showed normal vital signs, right upper quadrant pain on palpation and a focal pyogenic infection of molar 36 with an open root canal, which had been symptomatic for some weeks (Fig. 1). The physical examination was otherwise unremarkable. Laboratory results: white blood cell count $12.6 \times 1000 / \mu \mathrm{l}(4-11$ $\mathrm{x} 1000 / \mu \mathrm{l})$, C-reactive protein (CRP) $22.4 \mathrm{mg} / \mathrm{dl}(<0.5$ $\mathrm{mg} / \mathrm{dl})$, aspartate aminotransferase (AST) $33 \mathrm{U} / 1(<57$ $\mathrm{U} / \mathrm{l})$, alanine aminotransferase (ALT) $43 \mathrm{U} / 1 \quad(<45$ 


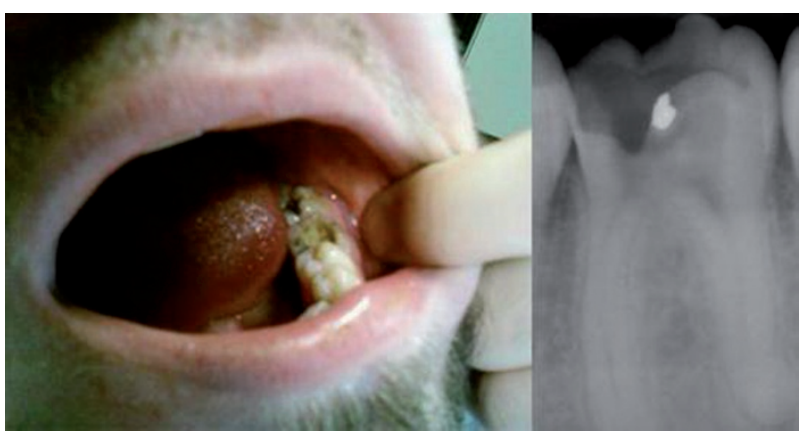

Fig. 1. Pyogenic infection of molare 36, showing an open root canal on $\mathrm{x}$-ray.

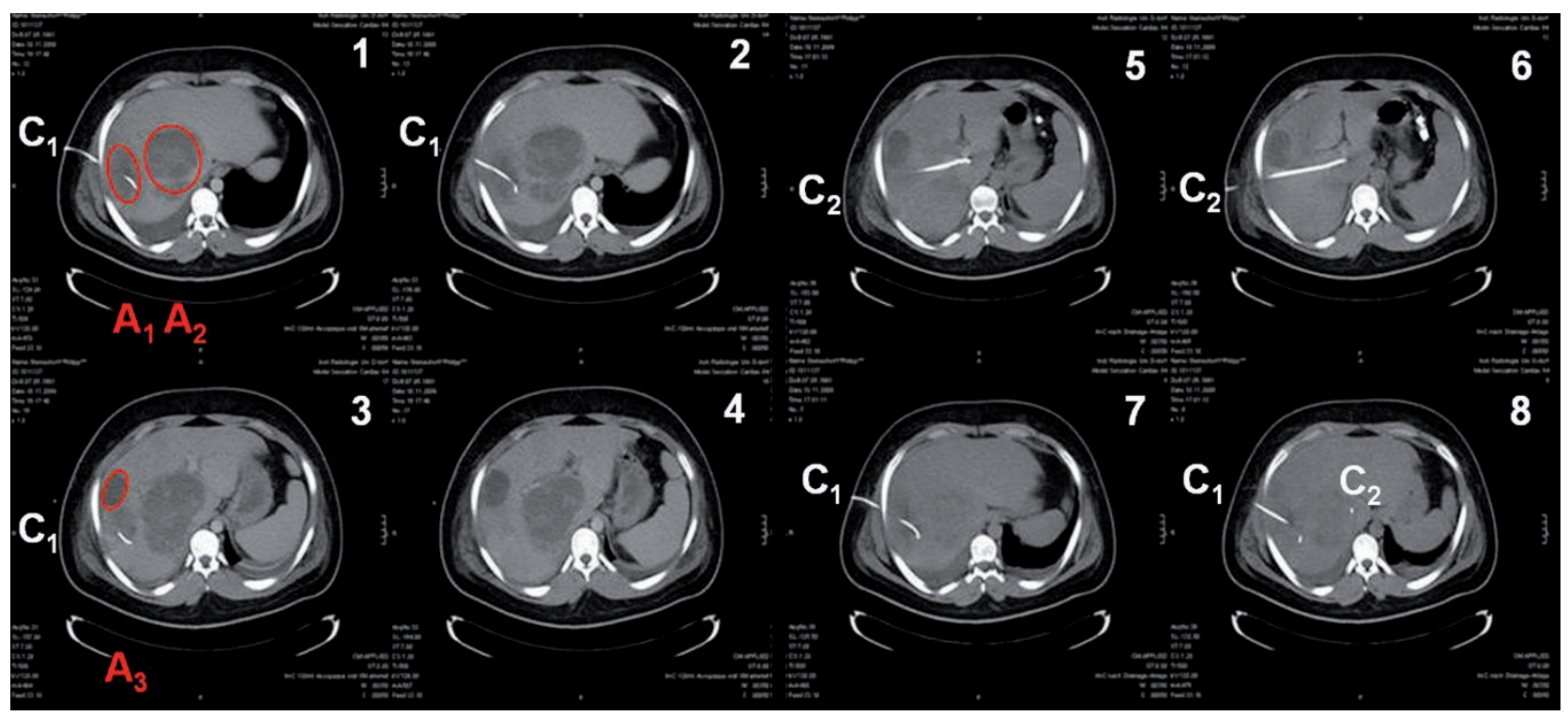

Fig. 2. (left: 1-4): location of the 3 abscesses (A1,A2,A3) eligible for percutaneous drainage: abscess 1 (A1) already drained by the sonographically inserted catheter 1 (C1). Still undrained abscess A3. [note the right sided pleural effusion]; (right: 5-8): CTguided insertion of catheter $\mathrm{C} 2$ in abscess A2.
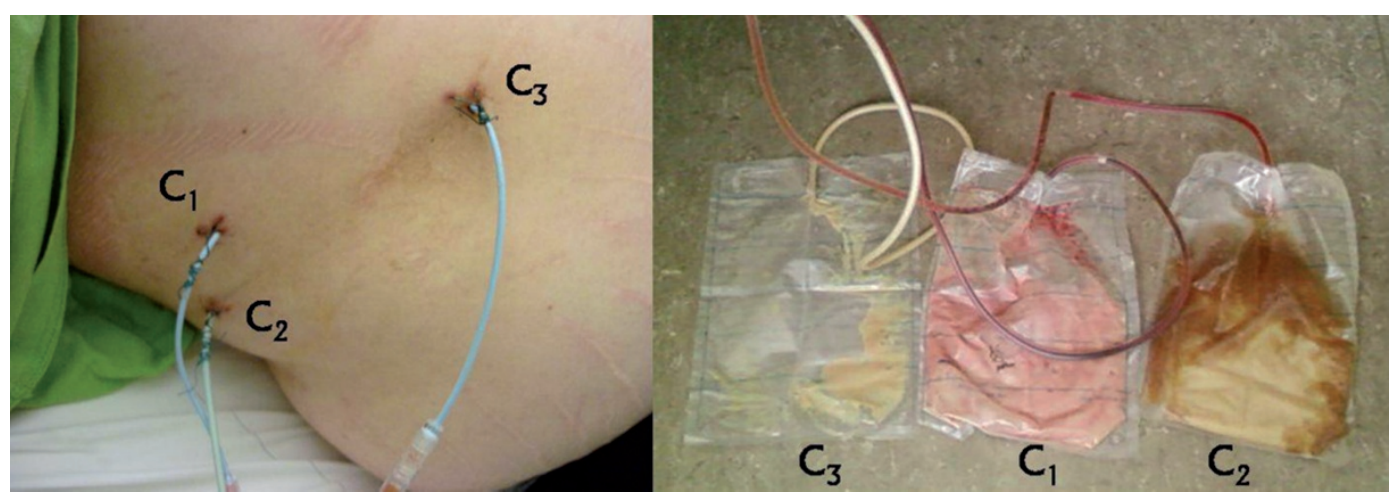

Fig. 3. Drainages in situ.

$\mathrm{U} / \mathrm{l}), \boldsymbol{\gamma}$-glutamyltransferase $(\gamma$-GT) $158 \mathrm{U} / 1(<55 \mathrm{U} / \mathrm{l})$, alkaline phosphatase (AP) $177 \mathrm{U} / 1$ (40-129 U/1), hemoglobin $11.2 \mathrm{~g} / \mathrm{dl}(14-18 \mathrm{~g} / \mathrm{dl})$, hematocrit $33.6 \%$ $(42-50 \%)$, platelets $350 \times 1000 / \mu \mathrm{l}(150-400 \times 1000 / \mu \mathrm{l})$, prothrombin time $79 \%(70-130 \%)$, international normalized ratio $1.2(0.8-1.2)$, partial thromboplastin time 29 seconds (26-36 seconds). Abdominal sonography revealed an enlarged liver (cranio-caudal $156 \mathrm{~mm}$; dorso-ventral $180 \mathrm{~mm}$ ) with homogenous hyperechoic parenchyma (showing signs of hepatic steatosis) and multiple hypoechoic lesions (the biggest lesion measuring $98 \times 95 \times 98 \mathrm{~mm})$, splenomegaly (150 x 40mm), minimal perihepatic and perisplenic ascites, and a rightsided pleural effusion (Fig. 5). The presence of an in- fective endocarditis was ruled out by transoesophageal echocardiography. The already isolated "gram-positive cocci" from fine needle aspiration were finally identified as Streptococcus intermedius (Streptococcus anginosus group) being sensitive to ampicillin, mezlocillin, piperacillin, amoxicillin/clavulanic acid, piperacillin/ tazobactam, cefaclor, cefuroxim, cefotaxim, doxycycline, erythromycin, clindamycin, levofloxacin, vancomycin and the already started empirical antibiotic treatment with penicillin and imipenem/cilastin. The isolate showed resistance to ciprofloxacin, cotrimoxazol, and gentamicin. Because of their number and size, the liver abscesses were evaluated for percutaneous drainage. Of the 5 sonographically identified abscess 


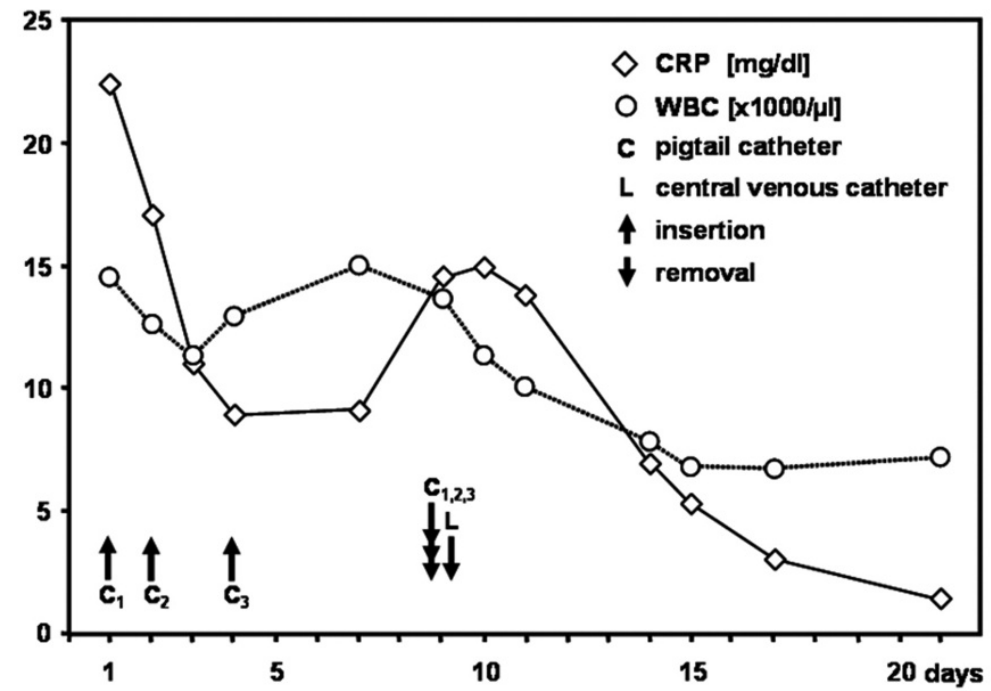

Fig. 4. Clinical course of laboratory parameters and interventions (Note: the central venous catheter was already in place on referral of the patient).

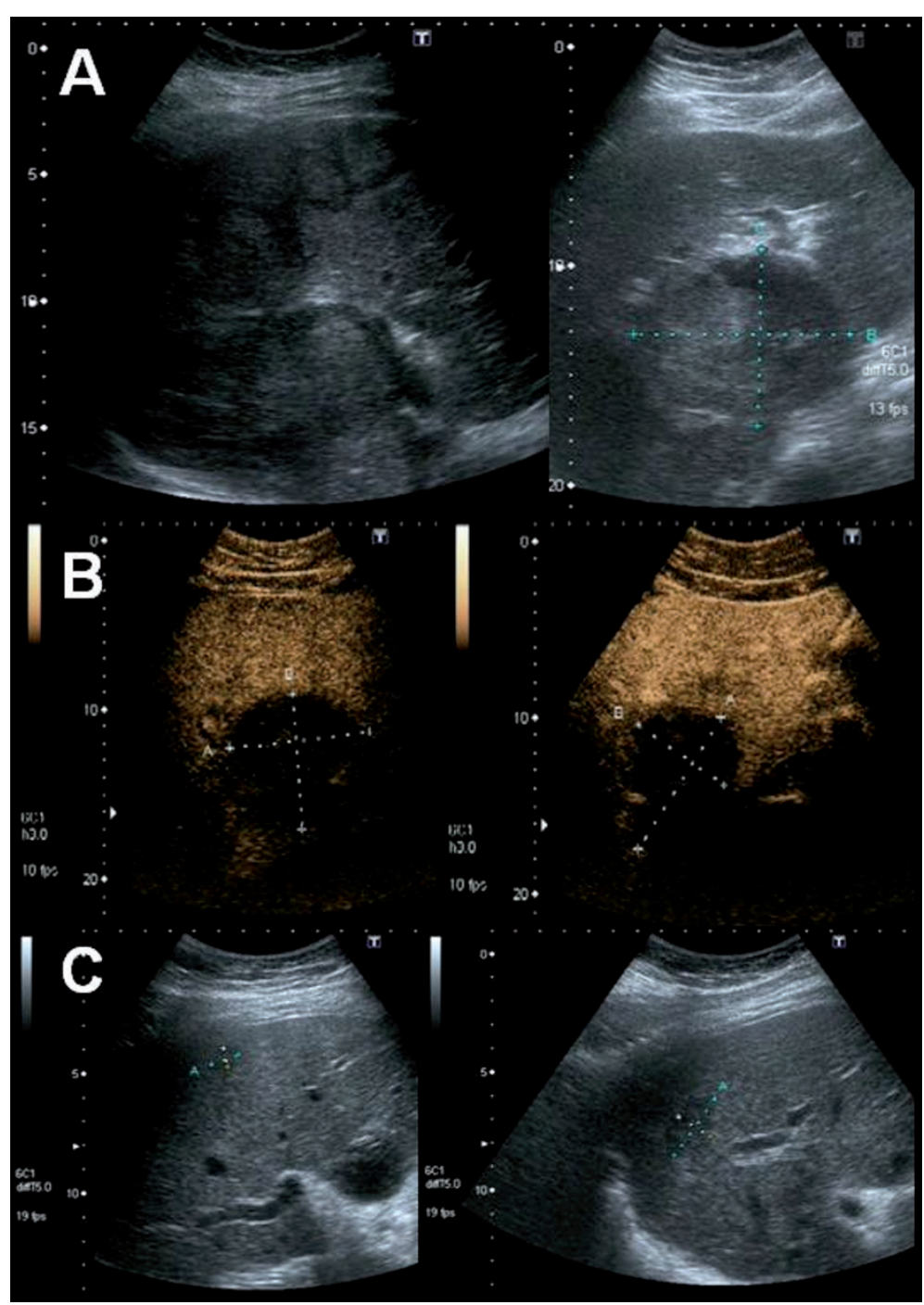

Fig. 5. A: Sonography on admission, B: Contrast media sonography on day 5 after admission, C: Sonographical follow-up 10 days after discharge cavities 3 were eligible for percutaneous drainage: 2 cavities were successively drained by ultrasound guided puncture and insertion of $10 \mathrm{~F}$ pigtail catheters (C1,C3). A third 10F pigtail catheter was inserted by CT guidance (C2)(Fig. 2). The catheters were left in place until the drainage of putrid material ceased (C1: 8d, C2: 7d, C3: 5d). Altogether $850 \mathrm{ml}$ pus were evacuated (C1: $250 \mathrm{ml}, \mathrm{C} 2: 500 \mathrm{ml}$, C3: $100 \mathrm{ml}$ )(Fig. 3). The righ-sided pleural effusion was punctured in order to rule out an infected effusion or a pleural emphyema. The laboratory results showed a sterile exsudate. The volume of the pleural effusion continuously declined during treatment, suggesting a parainfectious process. With Streptococcus intermedius (Streptococcus anginosus group) being a part of the normal commensal flora of the mouth the pyogenic dental infection is highly suspicious of being the inital focus with subsequent hematogenous spread to the liver. Under antimicrobial treatment, catheterization of the liver abscesses and removal of the suspected causative focus - by extracting the infected molar - the infection parameters (CRP, WBC) dropped, while repeated sonographic controls showed a good regression of the abscess cavity sizes (Fig. 5). Around the 4th day of treatment the WBC and CRP levels stopped falling (Fig. 4). A sonographic control showed no evidence of persisting abscess cavities and no new evolving foci. When the infection parameters did not show any improvement over the next consecutive days and the CRP level finally started rising again around the 9th day, we reevaluated the situation: The clinical condition of the patient was stable. As the drainage of putrid material via the pigtail catheters had ceased, all 3 catheters were removed and the central venous catheter (although not showing any sign of catheter-site infection) was removed too. The successive cultures of putrid material obtained on puncture and catheter insertions showed sterile results, while microscopy yielded the picture of an anaerobic mixed flora (gram positive cocci and gram negative - partly coccoid - rods). To extend the anaerobic coverage, we escalated the antimicrobial treatment by adding metronidazole. After removal of the pigtail catheters and the central venous line, the inflammatory parameters immediately continued dropping (Fig. 4). Later the culture of the central venous catheter tip revealed the growth of a coagulase negative staphylococcus, retrospectively suggesting a causative catheter related infection. The further clinical course was unremarkable. After 3 weeks of intravenous treatment the antibiotic 
combination of imipenem/cilastin, penicillin $G$ and metronidazole was deescalated to oral levofloxacin and metronidazole and we discharged the patient on day 21 after admission. Sonographically the former liquid parts of the three drained abscess cavities had disappeared and the focal findings were declining. The size of the right-sided pleural effusion was also declining. Another 10 days later the patient was well, had no physical complaints, normal laboratory parameters (WBC $6 \times 1000 / \mu \mathrm{l}, \mathrm{CRP} 0,4 \mathrm{mg} / \mathrm{dl}$ ), and further resolving findings on ultrasound investigation (Fig. 5). On follow-up another 14 days later the patient was well, had no physical complains, the laboratory parameters were normal (WBC 5,8 x1000/ $\mu$ l, CRP 0,3 mg/dl), on ultrasound investigation the right sided pleural effusion had completely resolved, two of the three drained abscess cavities were not longer detectable, and of the third abscess only a minimal residuum of $11 \times 6 \mathrm{~mm}$ was still detectable. Because of the excellent imagemorphological resolution and the absence of clinical and paraclinical signs of a persisting infection we stopped the antibiotic treatment (after a total time of around 7 weeks).

\section{CONCLUSION}

Our reported case corroborates published literature reporting Streptococcus intermedius as a cause of liver abscesses emerging from dental infectious foci even in previously healthy patients without underlying innate or aquired immunodeficiency [9, 24]. The case illustrates the potential danger and underestimated risk associated with untreated dental infections.

\section{REFERENCES}

1. Mirzanejad Y., Stratton C.W. Streptococcus anginosus Group. In: Mandell GL, Bennett JE, Dolin R, editors. Principles and practice of infectious diseases. Philadelphia: Elsevier Churchill Livingstone, 2005:2451-2455.

2. Whiley RA, Beighton D, Winstanley TG, Fraser HY, Hardie JM. Streptococcus intermedius, Streptococcus constellatus, and Streptococcus anginosus (the Streptococcus milleri group): association with different body sites and clinical infections. J Clin Microbiol. 1992;30(1): 243-244.

3. Molina JM, Leport C, Bure A, Wolff M, Michon C, Vilde JL. Clinical and bacterial features of infections caused by Streptococcus milleri. Scand J Infect Dis. 1991;23(6):659666.

4. Robertson D, Smith AJ. The microbiology of the acute dental abscess. J Med Microbiol. 2009;58(2):155-162.

5. Gossling J. Occurrence and pathogenicity of the Streptococcus milleri group. Rev Infect Dis. 1988;10(2):257-285.

6. Whitworth JM. Lancefield group F and related streptococci. J Med Microbiol. 1990; 33(3):135-151.

7. Woo PC, Tse H, Chan KM, Lau SK, Fung AM, Yip KT et al. "Streptococcus milleri" endocarditis caused by Streptococcus anginosus. Diagn Microbiol Infect Dis. 2004; 48(2):81-88.

8. Rashid RM, Salah W, Parada JP. 'Streptococcus milleri' aortic valve endocarditis and hepatic abscess. J Med Microbiol. 2007;56(2):280-282.

9. Tran MP, Caldwell-McMillan M, Khalife W, Young VB. Streptococcus intermedius causing infective endocarditis and abscesses: a report of three cases and review of the literature. BMC Infect Dis. 2008;8:154.
10. Mathisen GE, Johnson JP. Brain abscess. Clin Infect Dis. 1997;25(4):763-779.

11. Libertin CR, Hermans PE, Washington JA. Beta-hemolytic group F streptococcal bacteremia: a study and review of the literature. Rev Infect Dis. 1985;7(4):498-503.

12. Murray HW, Gross KC, Masur H, Roberts RB. Serious infections caused by Streptococcus milleri. Am J Med. 1978;64(5):759-764.

13. Hardwick RH, Taylor A, Thompson MH, Jones E, Roe AM. Association between Streptococcus milleri and abscess formation after appendicitis. Ann R Coll Surg Engl. 2000;82(1):24-26.

14. Shinzato T, Saito A. The Streptococcus milleri group as a cause of pulmonary infections. Clin Infect Dis. 1995;21 Suppl 3:S238-S243.

15. Wong CA, Donald F, Macfarlane JT. Streptococcus milleri pulmonary disease: a review and clinical description of 25 patients. Thorax. 1995;50(10):1093-1096.

16. Marinella MA, Harrington GD, Standiford TJ. Empyema necessitans due to Streptococcus milleri. Clin Infect Dis. 1996;23(1):203-204.

17. Porta G, Rodriguez-Carballeira M, Gomez L, Salavert M, Freixas N, Xercavins $M$ et al. Thoracic infection caused by Streptococcus milleri. Eur Respir J. 1998;12(2):357362.

18. Whiley RA, Hall LM, Hardie JM, Beighton D. A study of small-colony, beta-haemolytic, Lancefield group C streptococci within the anginosus group: description of Streptococcus constellatus subsp. pharyngis subsp. nov., associated with the human throat and pharyngitis. Int J Syst Bacteriol. 1999;49 Pt 4:1443-1449.

19. Shishido H, Watanabe K, Matsumoto K, Murakami K, Sato K. Primary purulent mediastinitis due to Streptococcus milleri. Respiration. 1997;64(4):313-315.

20. Houston BD, Crouch ME, Finch RG. Streptococcus MG-intermedius (Streptococcus milleri) septic arthritis in a patient with rheumatoid arthritis. J Rheumatol. 1980; 7(1):89-92.

21. Jackson DS, Welch DF, Pickett DA, Mukwaya GM, Kuhls TL. Suppurative infections in children caused by non-beta-hemolytic members of the Streptococcus milleri group. Pediatr Infect Dis J. 1995;14(1):80-82.

22. Lunn JV, Rahman KJ, Macey AC. Streptococcus milleri infection. J Hand Surg Br. 2001; 26(1):56-57.

23. Young KA, Allaker RP, Hardie JM, Whiley RA. Interactions between Eikenella corrodens and 'Streptococcus milleri-group' organisms: possible mechanisms of pathogenicity in mixed infections. Antonie Van Leeuwenhoek. 1996;69(4):371-373.

24. Quinlivan D, Davis TM, Daly FJ, Darragh H. Hepatic abscess due to Eikenella corrodens and Streptococcus milleri: implications for antibiotic therapy. J Infect. 1996; 33(1):47-48.

Received: February 20, 2010 / Accepted: May 21, 2010

Address for correspondence:

Dr. med. Andreas Neumayr

Klinik für Gastroenterologie, Hepatologie und Infektiologie

Universitätsklinikum Düsseldorf

Heinrich-Heine-Univeristät

Moorenstrasse 5

40225 Düsseldorf

Germany

Tel.: $\quad+49(0) 211-81-17028$

Fax : +49(0)211-81-18752

Email: andreas_neumayr@hotmail.com 